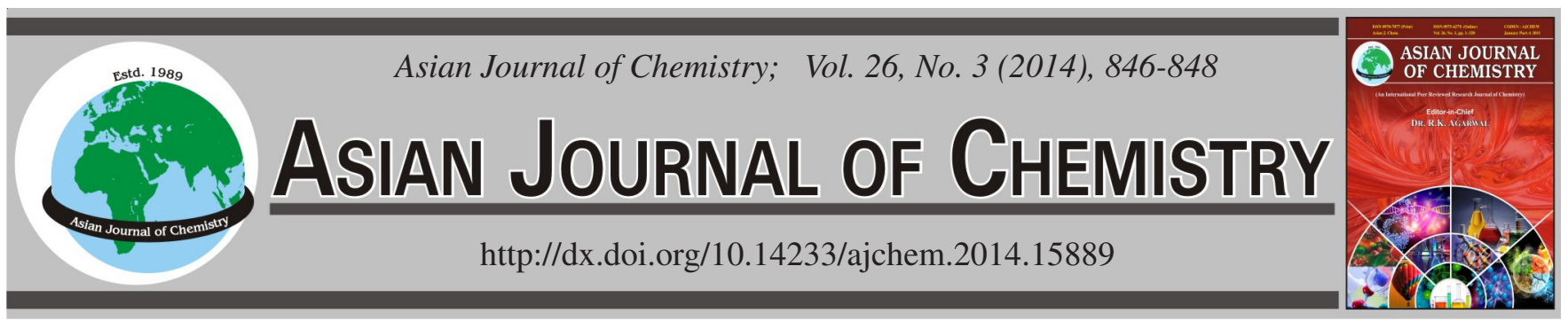

\title{
Quantification of Thiamine in Edible Bird's Nest by HPLC with Fluorescence Detection
}

\author{
Peishan Teo ${ }^{*,}$, Fucui MA ${ }^{*, \dagger}$ and Daicheng Liu ${ }^{*}$
}

Key Laboratory of Animal Resistance, College of Life Science, Shandong Normal University, 88 East Wenhua Road, Jinan 250014, P.R. China

*Corresponding authors: Tel/Fax: +86053186180745; E-mail: shanteo@hotmail.com, mafucui@hotmail.com, liudch@sdnu.edu.cn $\dagger$ These authors contribute equally to the work.

Keywords: HPLC, Edible bird's nest, Thiamine, Nutraceutical food.

\section{INTRODUCTION}

Edible bird's nest is an expensive traditional Chinese medicine and nutraceutical food. It has important medicinal values $^{1}$. The swiftlet is a type of insectivorous bird and predominately inhabits in the limestone caves. They are found in the Indian Ocean, South and South East Asia, North Australia and the Pacific Islands. Swiftlets distribute mainly in Asian countries, such as Malaysia, Indonesia, Thailand, Vietnam, Philippines and China. Indonesia and Malaysia Borneo are the leading producer nations of edible bird's nest. The great consumer market of the edible bird's nest is Hong Kong and the next is the ethnic Chinese of North America ${ }^{1-3}$.

Edible bird's nest contains many chemical compounds which include lipid (0.14-1.28 \%), ash (2.1\%), carbohydrate $(25.62-27.26 \%)$ and protein $(62-63 \%)$. Based on the previous reports, edible bird's nest contains many amino acids such as aspartic acid, threonine, serine, glutamic acid, glycine, alanine, valine, methionine, isoleucine, leucine, tyrosine, phenylalanine, lysine, histidine, arginine, tryptophan, cysteine and proline. Conversely, the study of vitamin was rarely conducted in the edible bird's nest, especially B-complex ${ }^{1}$. Thus, analysis and study of vitamin in edible bird bird's nest will be of more significance. Thiamine (3-[(4-amino-2-methyl-5- pyrimidinyl)methyl]5-(2-hydroxyethyl)-4-methylthiazolium chloride) is a watersoluble vitamin and also called vitamin B1, which is widely used for the additives of drinks and nutraceutical food products.
Analytical techniques for thiamine determination include capillary electrophoresis ${ }^{4}$, spectrophotometry ${ }^{5}$, voltammetry ${ }^{6}$ and $\mathrm{HPLC}^{7}$. The method of HPLC has been used widely for the determination of thiamine. To our best of knowledge, no work related to the stability indicating HPLC determination of thiamine in edible bird's nest has been reported in the current literature. Therefore, the aim of this study was to provide simple and rapid method of extraction and quantification of thiamine in the edible bird's nest.

\section{EXPERIMENTAL}

Unprocessed white edible bird's nest was obtained from CINRA Food Industries SDN. BHD (Malaysia). The bird's nests were processed as described by Guo et al. ${ }^{8}$. The grounded nest samples were used in the following experiments. A thiamine standard (T4625, $\geq 99 \%$ lyophilized powder) was purchased from Sigma Chemical Co. (St. Louis, MO, USA). All mobile phase solvents were of chromatographically grade.

Chromatographic conditions: The chromatograms of standards and samples were plotted by HPLC system consisting of LC-20AT Prominence (Shimadzu, Japan) and C18 analytical column $150 \mathrm{~mm} \times 4.6 \mathrm{~mm}, 5 \mu \mathrm{m}$ (Hypersil-ODS2). Thiamine was performed by using a mobile phase consisting of methyl alcohol and sodium acetate solution (34: 66) (v/v). The fluorescence detector was operated at $365 \mathrm{~nm}$ excitation wavelength and $475 \mathrm{~nm}$ emission wavelength. The flow rate was $1 \mathrm{~mL} / \mathrm{min}$ and the injection volume was $20 \mu \mathrm{L}$. 
Extraction method: The powdered sample $(4 \mathrm{~g})$ and hydrochloric acid $(50 \mathrm{~mL}, 0.1 \mathrm{~mol} / \mathrm{L})$ were added into the $250 \mathrm{~mL}$ conical flask. The conical flask was placed into a boiling water bath $\left(90-100{ }^{\circ} \mathrm{C}\right.$ ) for $0.5 \mathrm{~h}$. After cooling, the extract was adjusted to $\mathrm{pH} 4.0-4.5$ with sodium acetate $(2 \mathrm{~mol} / \mathrm{L})$. Then, the extract and Taka-Diastase solution $(5 \mathrm{~mL}, 100 \mathrm{~g} / \mathrm{L})$ were mixed and placed into boiling water bath $\left(45-50{ }^{\circ} \mathrm{C}\right)$ for $3 \mathrm{~h}$. After cooling, the extract was adjusted to $\mathrm{pH} 3.5$ with hydrochloric acid $(0.1 \mathrm{~mol} / \mathrm{L})$ and diluted to $100 \mathrm{~mL}$ with distilled water. The extract was filtered through a filter paper. The preparation of oxidizing agent was carried out by mixing potassium ferricyanide $(100 \mathrm{~mL}, 0.1 \mathrm{~g} / \mathrm{L})$ with sodium hydroxide solution $(150 \mathrm{~g} / \mathrm{L})$. The filtrate of the extract $(5 \mathrm{~mL})$ was mixed with potassium chloride $(1.5 \mathrm{~g})$, oxidizing agent $(3 \mathrm{~mL})$ and isobutyl alcohol $(10 \mathrm{~mL})$ and shaked for $2 \mathrm{~min}$. The supernatant was filtered through a cellulose acetate filter $(0.45 \mathrm{pm})$. Then, the extract was used for the chromatographic determination of thiamine.

Standard solution preparation: Standard thiamine $(50 \mathrm{mg})$ was accurately weighed and was processed as mentioned above (extraction method). Peak area of standard was plotted in the calculations.

Limit of detection and limit of quantitation: The determinations of the minimum detectable level LOD and minimum quantifiable level LOQ were defined as the signal-to-noise ratio $3: 1$ and 10:1.

Recovery: The average recovery was obtained by the determined concentrations as a percentage of the original concentrations. Every sample solution of the same concentration was injected at least three times.

Calculations: The computational methods were as follows: $\mathrm{X}=(\mathrm{C} \times \mathrm{A} \times \mathrm{V}) /(\mathrm{M} \times 10 \times \mathrm{As})$

where, $\mathrm{X}$ : the amount of thiamine $(\mu \mathrm{g} / \mathrm{g})$; $\mathrm{C}$ : standard thiamine $(\mu \mathrm{g} / \mathrm{mL}) ; \mathrm{A}$ : peak area of sample; $\mathrm{V}$ : standard solution $(\mathrm{mL})$; As: peak area of extract; M: weight of sample.

\section{RESULTS AND DISCUSSION}

Thiamine has many benefits for our body which is an essential part of converting carbohydrates to energy. It is necessary for the proper functioning of the musculature system, the heart and especially the nervous system. Thiamine is used to improve focus and concentration. It exerts beneficial effects on Wernicke-Korsakoff syndrome which occurs in long-term alcoholics as well as on Alzheimer's disease?

Deficiencies in thiamine causes a variety of negative effects on human body. Muscle weakness, numbness in the extremities and physical incoordination could all be results of thiamine deficiency ${ }^{10}$. Lack of thiamine can also lead to congestive heart failure and lung congestion following enlargement of the heart ${ }^{11}$. The nervous system may suffer damage which may even lead to death due to thiamine deficiency and such mental symptoms as fatigue, confusion and psychosis will appear ${ }^{9}$.

Many literatures have been focused on the analysis of components of edible bird's nest and on the nest's biological and medicinal functions. It is highly acclaimed as a catholicon and is a comprehensive health food. The determination of proteins, carbohydrates, inorganic salts and various kinds of elements in the edible bird's nest reveal its important nutritional value. The element component consists of sodium, potassium, calcium, magnesium, phosphorus, iron, sulfur, barium, strontium, silicon, aluminium, manganese, zinc, copper, molybdenum, cobalt, germanium, selenium, nickel, vanadium, chromium, palladium, cadmium and mercury. The highest content of calcium and sulfur are 1298-12658 ppm and 7002 ppm, respectively. At present, components containing sulfur in the edible bird's nest which include sulfur-containing amino acid (methionine and cysteine) and sulfur-containing vitamin B complex (biotin). The study of vitamin was rarely conducted in the edible bird's nest, especially B-complex ${ }^{1-3,12}$. At the present study, thiamine which sulfur-containing vitamin B complex was discovered in the edible bird's nest. The traditional medicinal value of edible bird's nest includes its use in anti-aging, anti-cancer, immunity-enhancing, dissolving phlegm, alleviating asthma, suppressing cough, curing tuberculosis, improving the voice, stomach ulcers, haematemesis, general debility and asthenia and increasing energy and metabolism, etc. The bioactivities and nutritional value of the edible bird's nest include the potential for mitogenic response, epidermal growth factor (EGF)-like activity, antiinfluenza virus, hemagglutination-inhibitory activity, lectin-binding activity, improvement of bone strength and dermal thickness and hormone content etc. ${ }^{1}$.

The sample was extracted through hydrolyzed protein, enzymolysis and oxidation. This extraction method could be used to obtain pure thiamine. Meanwhile the effect of the impurity on the detection of thiamine was reduced. The edible bird's nest has been used as traditional Chinese medicine for centuries. It was recorded that edible bird's nest can increase energy and metabolism, speed recovery from illness and surgery and improve concentration etc. ${ }^{1}$. These functions can be associated with Vitamin B1 content to some extent.

An analytical technique of HPLC is widely used, which is mainly because of its advantages, such as rapid, simple, low-cost and low limit of detection. The fluorescence detection has high sensitivity. Because content of thiamine in the edible bird's nest is very low, HPLC was chosen.

The limit of detection was found to be $0.016 \mu \mathrm{g} / \mathrm{mL}$ and the limit of quantitation was $0.048 \mu \mathrm{g} / \mathrm{mL}$. The average recovery was $101.9 \%$. In Figs. 1 and 2, the standard peak and sample peak was aligned and peak of 8.5 min was recorded. The analysis method of thiamine is precise, specific, accurate and stable by HPLC and best proof was given in Fig. 1 and Fig. 2. Total content of thiamine was $13 \mu \mathrm{g} / \mathrm{g}$ in the edible bird's nest.

In our present study, content of thiamine in the edible bird's nest was determined. Thiamine has many medicinal and biological functions. The medicinal and biological functions of edible bird's nest may be elucidated more clearly. As HPLC is fast, simple and accurate, determining thiamine in the edible bird's nest could be used as an assistant method when authenticate edible bird's nest.

\section{Conclusion}

The proposed analytical HPLC method is precise, specific, accurate and stable. This method may be applied in routine analysis of thiamine in edible bird's nest and it may be a useful method to determine adulteration. 


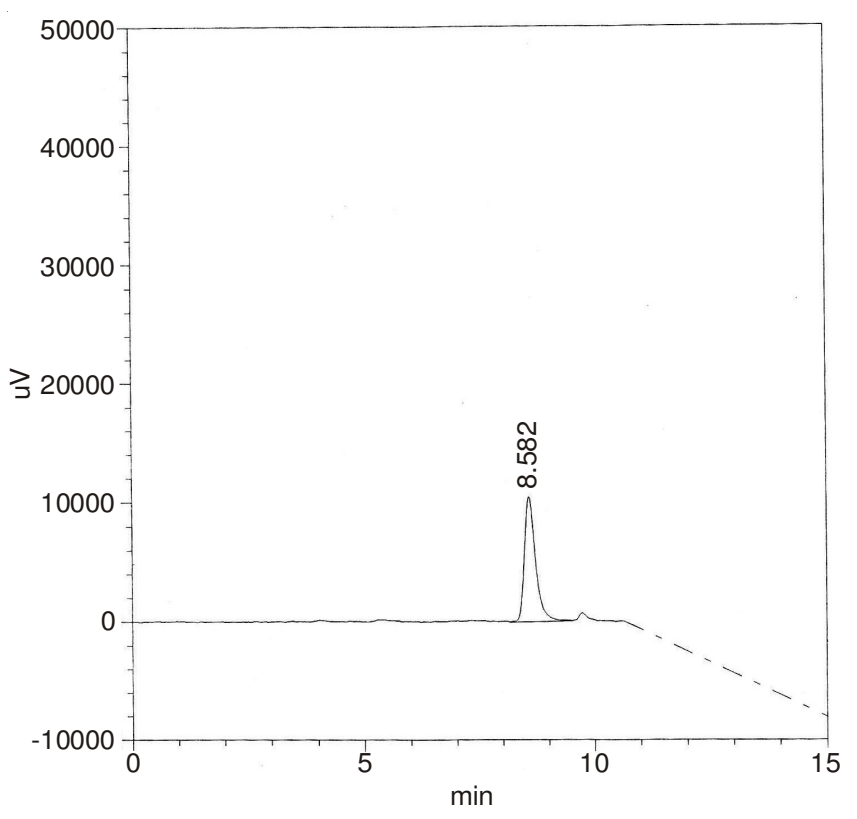

Fig. 1. Peak of standard ( $365 \mathrm{~nm}$ excitation wavelength, $475 \mathrm{~nm}$ emission wavelength)

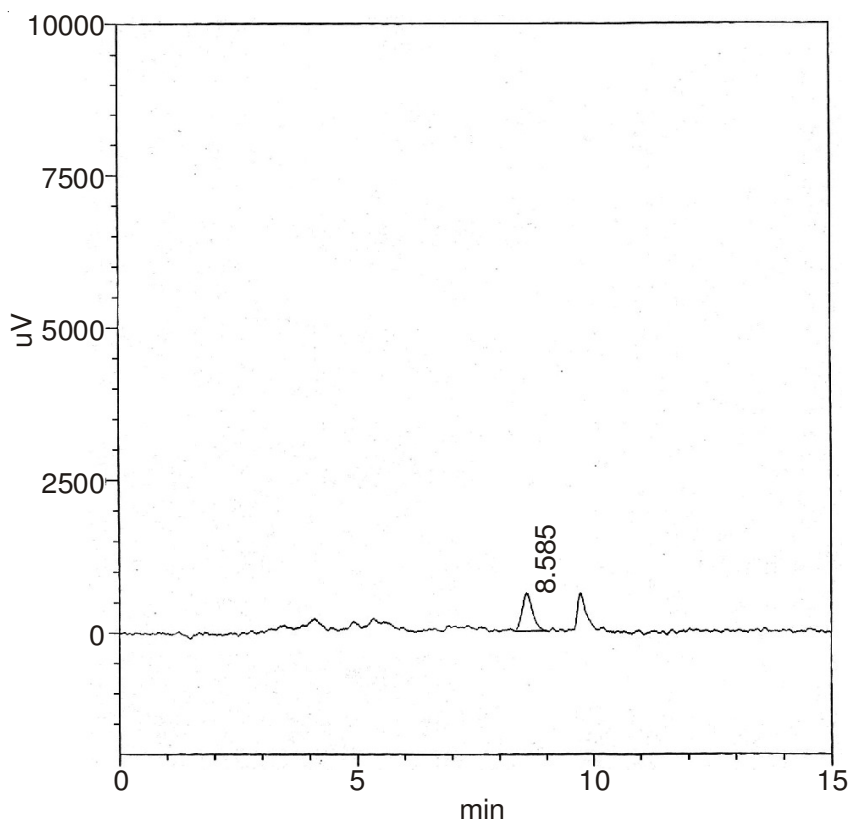

Fig. 2. Peak of sample (365 $\mathrm{nm}$ excitation wavelength, $475 \mathrm{~nm}$ emission wavelength)

\section{REFERENCES}

1. F. Ma and D. Liu, Food Res. Int., 48, 559 (2012).

2. M.F. Marcone, Food Res. Int., 38, 1125 (2005).

3. J.J. Hobbs, Biodivers. Conserv., 13, 2209 (2004).

4. M. Schreiner, E. Razzazi and W. Luf, Nahrung, 47, 243 (2003).

5. S. Liu, Z. Zhang, Q. Liu, H. Luo and W. Zheng, J. Pharmaceut. Biomed, 30, 685 (2002).

6. K. Srividya and N. Balasubramanian, Chem. Pharm. Bull. (Tokyo), 45, 2100 (1997).

7. Z. Chen, B. Chen and S. Yao, Anal. Chim. Acta, 569, 169 (2006).

8. C.T. Guo, T. Takahashi, W. Bukawa, N. Takahashi, H. Yagi, K. Kato, K.I.P.J. Hidari, D. Miyamoto, T. Suzuki and Y. Suzuki, Antiviral Res., 70, 140 (2006).

9. S.S. Jhala and A.S. Hazell, Neurochem. Int., 58, 248 (2011).

10. H. Koike, H. Watanabe, A. Inukai, M. Iijima, K. Mori, N. Hattori and G. Sobue, J. Neurol. Sci., 249, 175 (2006).

11. H. Ozawa, Y. Homma, H. Arisawa, F. Fukuuchi and S. Handa, Nutrition, 17, 351 (2001).

12. P. Teo, D. Liu and M. Dai, Asian J. Chem, 24, 5573 (2012). 